\title{
Triptolide induces apoptosis in human adrenal cancer NCI-H295 cells through a mitochondrial-dependent pathway
}

\author{
PING-PING WU ${ }^{1}$, KUO-CHING LIU ${ }^{2}$, WEN-WEN HUANG ${ }^{3}$, CHIA-YU MA ${ }^{5}$, \\ HUNG LIN ${ }^{4}$, JAI-SING YANG ${ }^{4 *}$ and JING-GUNG CHUNG ${ }^{3,6^{*}}$ \\ ${ }^{1}$ School of Pharmacy, Departments of ${ }^{2}$ Medical Laboratory Science and Biotechnology, ${ }^{3}$ Biological Science and \\ Technology and ${ }^{4}$ Pharmacology, China Medical University, Taichung 404; ${ }^{5}$ Department of Food and \\ Beverage Management, Technology and Science Institute of Northern Taiwan, Peitou, Taipei 112; \\ ${ }^{6}$ Department of Biotechnology, Asia University, Taichung 413, Taiwan, R.O.C.
}

Received August 26, 2010; Accepted October 25, 2010

DOI: $10.3892 /$ or.2010.1080

\begin{abstract}
Triptolide, the main active component obtained from Tripterygium wilfordii Hook. f, has been reported to present potent immunosuppressive and anti-inflammatory biological activities. It has been previously shown that due to the cytotoxicity of triptolide it has a limited use in the clinic. Although numerous studies have shown that triptolide induced apoptosis in many human cancer cells there is no report to show triptolide-induced apoptosis in human adrenal cancer cells. We treated the human adrenal cancer NCI-H295 cells with triptolide in vitro and investigated its cytotoxic effects. The cytotoxicity was examined and quantitated by $3-(4,5-$ dimethylthiazol-2-yl)-2,5-diphenyl-tetrazolium bromide (MTT) assay and the viability of inhibition and apoptosis was determined by flow cytometric assay, using propidium iodide (PI) staining for apoptosis. Flow cytometric assay also used for the determination of reactive oxygen species (ROS) production and the levels of mitochondrial membrane potential $\left(\Delta \Psi_{m}\right)$, and the caspase-3 and -9 activation in NCIH295 cells. Western blotting was used for examining the changes of apoptotic associated proteins. The results indicated that triptolide induced cytotoxicity (decreased the percentage of viable cells) and induced sub-G1 phase
\end{abstract}

Correspondence to: Dr Jing-Gung Chung, Department of Biological Science and Technology, China Medical University, No. 91, Hsueh-Shih Road, Taichung 40402, Taiwan, R.O.C. E-mail: jgchung@mail.cmu.edu.tw

Dr Jai-Sing Yang, Department of Pharmacology, China Medical University, No. 91, Hsueh-Shih Road, Taichung 404, Taiwan, R.O.C. E-mail: jaising@mail.cmu.edu.tw

${ }^{*}$ Contributed equally

Key words: triptolide, Chinese herbal medicine, apoptosis, human adrenal cancer NCI-H295 cells, mitochondrial-dependent pathway (apoptosis) occurring in NCI-H295 cells and those effects are dose-dependent. Results also showed that triptolide promoted the production of ROS and decreased the levels of $\Delta \Psi_{m}$ in examined NCI-H295 cells. The results showed that triptolide promoted the levels of cytochrome c, Apaf-1, AIF, Endo G, caspase- 9 and -3 which were analyzed by Western blotting. These results suggest that triptolide is able to induce apoptosis on NCI-H295 cells through the mitochondrial-dependent signal pathway.

\section{Introduction}

Triptolide, is a diterpenoid triepoxide, which is isolated from the plant Tripterygium wilfordii Hook. $\mathrm{f}$ (a member of the Celastraceae family) (1) that has been use in Chinese traditional medicine for two centuries. In patients, triptolide has been reported to treat a variety of autoimmune diseases, including rheumatoid arthritis; nephritis; and systemic lupus erythematosus and as immunosuppressant (2-5).

Besides the anti-inflammatory and immunosuppressive activities, triptolide has been shown to have antitumor properties in a variety of human tumor cells via impairing cell growth and inducing apoptosis $(1,6-8)$. However, a subacute toxicological study from mice demonstrated that the kidney is one of the target organs for triptolide (9). However, the effect of triptolide on human adrenal cancer NCI-H295 cells has not yet been investigated. Thus, we tried to identify the mechanism of triptolide-induced apoptosis in human adrenal cancer cells in vitro.

The present study was focused to define, for the first time, the anticancer effects of triptolide in treating human adrenal cancer NCI-H295 cells. We investigated whether triptolide was able to mediate the inhibition of cell growth and induction of apoptosis in human adrenal cancer NCI-H295 cells. Furthermore, to identify a potential signal pathway for the anticancer effect in triptolide treated adrenal cancer cells. Our results demonstrated that triptolide induced NCI-H295 cells death in apoptotic manner through a mitochondrialdependent pathway. Furthermore, caspase- 3 and -9 activations are also observed during the course of apoptosis in NCIH295 cells. 


\section{Materials and methods}

Materials and chemicals. Triptolide, potassium phosphate, dimethyl sulfoxide (DMSO), propidium iodide, triton X-100, Tris- $\mathrm{HCl}$, trypan blue, ribonuclease-A were purchased from Sigma Chemical Co. (St. Louis, MO, USA). RPMI1640 medium, L-glutamine, fetal bovine serum, penicillinstreptomycin, and trypsin-EDTA were obtained from Invitrogen Corp. (Carlsbad, CA, USA). The primary antibodies were obtained as follows: antibodies for caspase- 9 and caspase-3 were purchased from Cell Signaling Technology (Beverly, MA); antibodies for cytochrome c, Apaf-1, ß-actin, AIF, Endo $G$ and horseradish peroxidase (HRP)-linked goat anti-mouse $\mathrm{IgG}$, goat anti-rabbit $\mathrm{IgG}$, were purchased from Santa Cruz Biotechnology (Santa Cruz, CA). Caspase-9 inhibitor (Z-LEHD-FMK) and caspase-3 inhibitor (Z-DEVDFMK) were obtained from R\&D Systems (Minneapolis, MN, USA) then were dissolved in DMSO and diluted in cell culture medium before use.

Cell culture. The human adrenal cancer NCI-H295 cells were obtained from the Food Industry Research and Development Institute (Hsinchu, Taiwan). Cells were cultured in $75 \mathrm{~cm}^{2}$ tissue culture flasks at $37^{\circ} \mathrm{C}$ under a humidified $5 \% \mathrm{CO}_{2}$ atmosphere, with $90 \%$ RPMI-1640 medium with $2 \mathrm{mM}$ L-glutamine adjusted to contain $10 \%$ fetal bovine serum (Grand Island, NY), and 1\% penicillin-streptomycin (100 U/ml penicillin and $100 \mu \mathrm{g} / \mathrm{ml}$ streptomycin).

Examination of morphological changes and determination of cell viability and sub-G1 phase of cell cycle. Approximately $2 \times 10^{5}$ cells/well of NCI-H295 cells were grown in 12-well plates for $24 \mathrm{~h}$ before they were treated with triptolide at 0 , $50,100,150$ and $200 \mu \mathrm{M}$ and cells were incubated at $37^{\circ} \mathrm{C}$, $5 \% \mathrm{CO}_{2}$ and $95 \%$ air for $48 \mathrm{~h}$. For morphological changes, cells were examined and photographed under phase-contrast microscope as described previously $(10,11)$. For cell viability assay by 3-(4,5-dimethylthiazol-2-yl)-2,5-diphenyltetrazolium bromide (MTT) assay, cells $\left(1 \times 10^{4}\right.$ cells/well) were plated in 96-well plates and exposed to triptolide for $48 \mathrm{~h}$, MTT $(0.5 \mathrm{mg} / \mathrm{ml})$ was added to each well and cells were incubated for an additional $4 \mathrm{~h}$ at $37^{\circ} \mathrm{C}$. The medium was aspirated from the wells and the blue formazon product was dissolved in $100 \mu \mathrm{l}$ of DMSO. The plates were read at OD $570 \mathrm{~nm}$ using a spectrophotometric plate reader (Bio-Rad, Tokyo, Japan) as previously described $(12,13)$. Each data point was replicated in triplicate. For sub-G1 (apoptosis) determinations, the harvested cells were fixed gently in $70 \%$ ethanol at $4{ }^{\circ} \mathrm{C}$ overnight and then re-suspended in PBS containing $40 \mu \mathrm{g} / \mathrm{ml} \mathrm{PI}$ and $0.1 \mathrm{mg} / \mathrm{ml} \mathrm{RNase}$ and $0.1 \%$ Triton X-100 in the dark for $30 \mathrm{~min}$ at $37^{\circ} \mathrm{C}$. The cells were analyzed with a flow cytometer (Becton-Dickinson, San Jose, CA, USA) equipped with an argon ion laser at 488-nm wavelength (14).

Caspase-9 and -3 activities and caspase inhibitors inhibit triptolide-induced cell death in NCI-H295 cells. NCI-H295 cells $\left(5 \times 10^{5}\right.$ cells/well $)$ were pretreated with caspase- 3 inhibitor (Z-DEVD-FMK), a caspase-9 inhibitor (Z-LEHDFMK) and a pan-caspase inhibitor (Z-VAD-FMK) before cells were treated with $125 \mu \mathrm{M}$ of triptolide then were incubated at $37^{\circ} \mathrm{C}, 5 \% \mathrm{CO}_{2}$ and $95 \%$ air for $48 \mathrm{~h}$. NCI-H295 cells were harvested for determination of cell viability as described above. Cells were harvested by centrifugation and the cell pellets were added in lysis buffer $(50 \mathrm{mM}$ Tris- $\mathrm{HCl}$, $1 \mathrm{mM}$ EDTA, $10 \mathrm{mM}$ EGTA, $10 \mathrm{mM}$ digitonin and $2 \mathrm{mM}$ DTT) on ice for $10 \mathrm{~min}$. Cell lysates (50 $\mu \mathrm{g}$ proteins) after centrifugation at $15,000 \mathrm{x} \mathrm{g}$ at $4^{\circ} \mathrm{C}$ for $10 \mathrm{~min}$ were incubated with caspase- 3 and -9 specific substrates (Ac-DEVD-pNA and Ac-LEHD-pNA; R\&D Systems) with reaction buffer in a 96-well plate at $37^{\circ} \mathrm{C}$ for $1 \mathrm{~h}$. The caspase activity was determined by measuring OD 405 of the released pNA as describe elsewhere (15).

Reactive oxygen species (ROS) and mitochondrial membrane potential $\left(\Delta \Psi_{m}\right)$ determinations. NCI-H295 cells at a density of $2 \times 10^{5}$ cells/well were plated onto 12 -well plates and treated with $100 \mu \mathrm{M}$ of triptolide for $0,6,12,18$ and $24 \mathrm{~h}$. All cell samples were harvested then re-suspended in $500 \mu 1$ of DCFHDA $(10 \mu \mathrm{M})$ for $\operatorname{ROS}\left(\mathrm{H}_{2} \mathrm{O}_{2}\right)$ determination, suspended in $500 \mu \mathrm{l}$ of DiOC6 $(1 \mu \mathrm{mol} / \mathrm{l})$ for $\Delta \Psi_{m}$ determination and then incubated at $37^{\circ} \mathrm{C}$ for $30 \mathrm{~min}$ and analyzed by flow cytometry $(16,17)$. All fluorescence intensities were obtained from the mean intensity of the histogram constructed from 10,000 cells.

Western blotting of apoptosis associated proteins. NCI-H295 cells at a density of $1 \times 10^{7}$ cells/well were treated with $125 \mu \mathrm{M}$ of triptolide for $0,6,12$ and $24 \mathrm{~h}$. Cells from each treatment were collected by centrifugation and the total proteins were quantitated $(16,17)$. Equal amounts of lysate protein were run on $12 \%$ SDS-PAGE and electrophoretically transferred to PVDF membrane (Amersham Pharmacia Biotech, USA) then the blocked blots were incubated with specific primary antibody against cytochrome $c$, Apaf-1, AIF, Endo G, caspase- 9 and caspase- 3 overnight and further incubated for $1 \mathrm{~h}$ with HRP conjugated secondary antibody (Santa Cruz Biotechnology). Bound antibodies were detected by ECL kit as described previously (18-21).

Statistical analysis. Student's t-test was used to analyze differences between treated and control groups; $\mathrm{p}<0.05$, $\mathrm{p}<0.01, \mathrm{p}<0.001$.

\section{Results}

Triptolide induces morphological changes and decreases the percentage of viable human adrenal cancer NCI-H295 cells. To investigate the morphological changes and inhibition of cell viability of NCI-H295 cells after exposure to triptolide, the cells were assessed for their potential cytotoxicity on human adrenal cancer cells in vitro. Control cells appeared in the well spreading in spindle shape after observed with the phase contrast microscope (Fig. 1A). After treatment with 50, 100,150 and $200 \mu \mathrm{M}$ of triptolide for $24 \mathrm{~h}$, the cell shape changed to round (Fig. 1A), the round-shaped cells suggest that they were undergoing apoptosis initiated by triptolide. The results in Fig. 1 indicate that triptolide induced a significant increase in cell viability inhibition. 
A
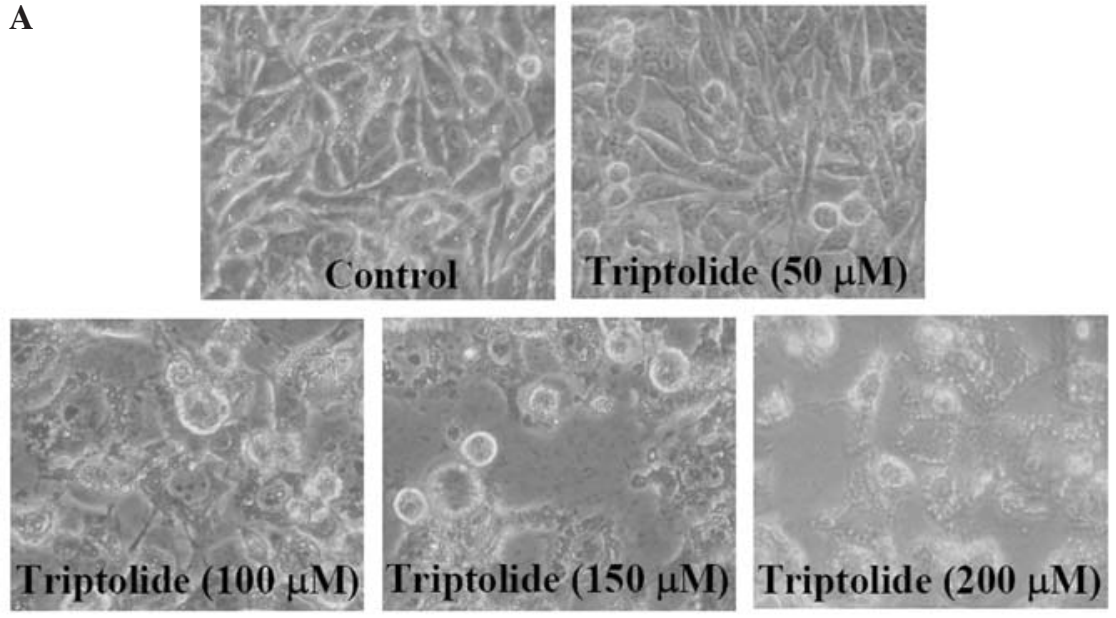

B

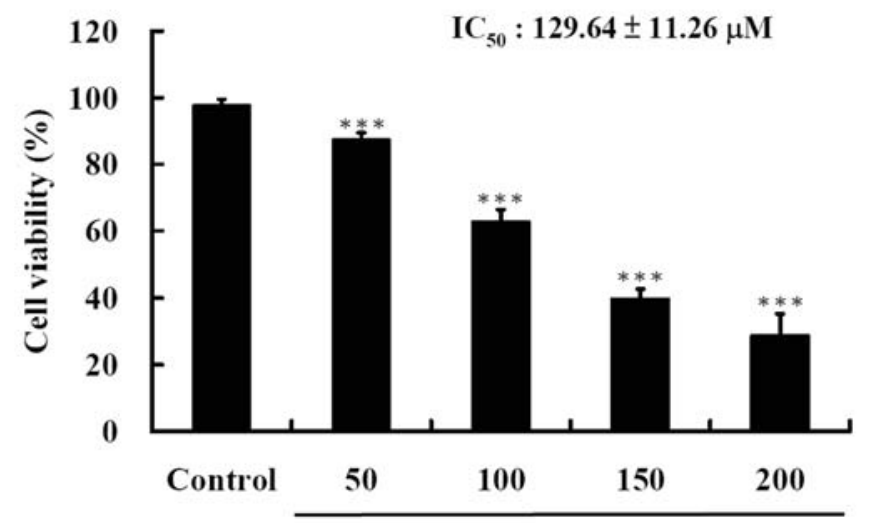

Figure 1. Triptolide induces morphological changes and decreases the percentage of viable human adrenal cancer NCI-H295 cells. NCI-H295 cells $\left(2 \times 10^{5}\right.$ cells/well) were grown in a 12 -well plate for $24 \mathrm{~h}$ then treated with 0 , $50,100,150$ and $200 \mu \mathrm{M}$ of triptolide for $48 \mathrm{~h}$. The cells were examined and photographed under contrast-phase microscope for morphological changes (A) and the total viable cells were determined (B) as described in Materials and methods. Each point is mean $\pm \mathrm{SD}$ of three experiments. ${ }^{* * *} \mathrm{P}<0.001$ indicates a significant difference from the control.

Triptolide $(\mu \mathrm{M})$

A

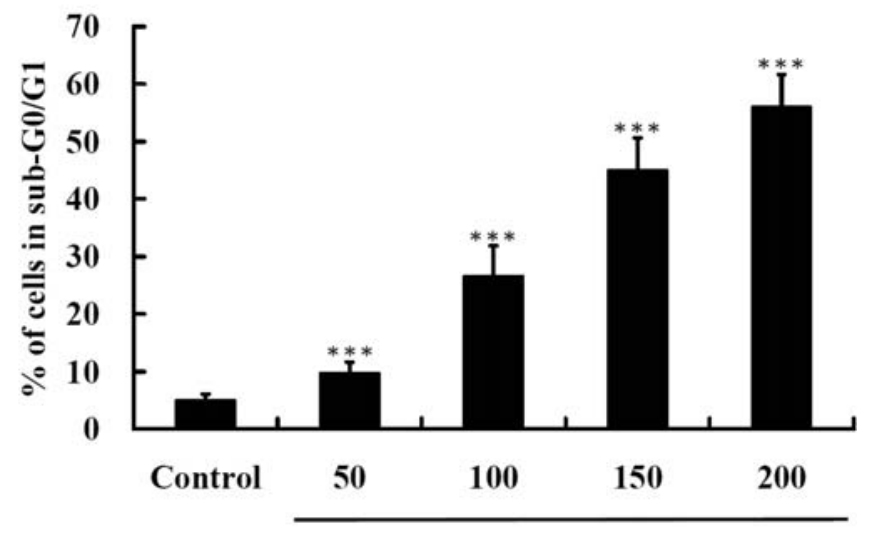

Triptolide $(\mu \mathbf{M})$
B

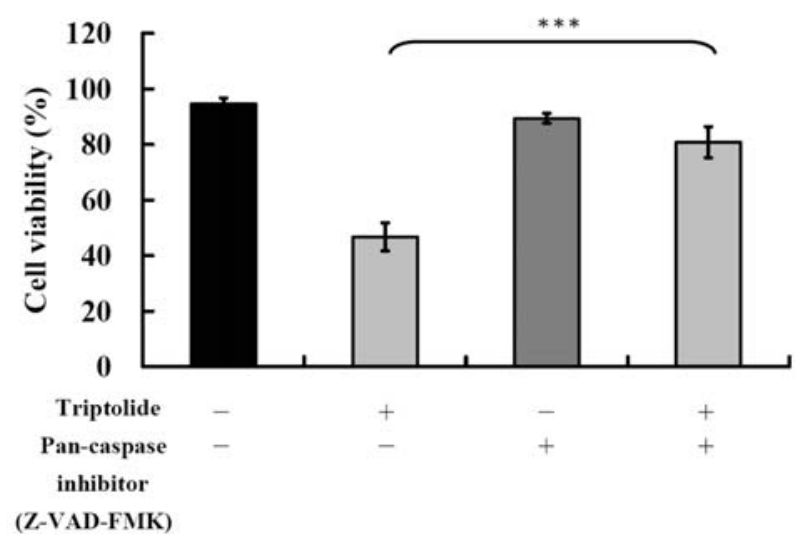

Figure 2. Triptolide induces apoptosis (sub-G1) and caspase inhibitors affect the viability of NCI-H295 cells in vitro. NCI-H295 cells $\left(5 \times 10^{5}\right.$ cells/well) were pre-treated with pan-caspase inhibitor (Z-VAD-FMK) and then were treated with 0,50,100,150 and $200 \mu \mathrm{M}$ of triptolide for $48 \mathrm{~h}$. Then cells were harvested for assaying the sub-G1 group of cell cycle (A) and the percentage of viable cells (B) were counted by flow cytometric assay as described in Materials and methods. The percentage of apoptosis was calculated. Each point is the mean $\pm \mathrm{SD}$ of three experiments. ${ }^{* * *} \mathrm{P}<0.001$ indicates a significant difference from the control.

Triptolide induces apoptosis (sub-G1) and caspase inhibitors affect the viability of NCI-H295 cells in vitro. It is well documented that cells undergoing early apoptosis can be seen in the sub-G1 phase of the cell cycle. NCI-H295 cells after exposure to various doses of triptolide were harvested and analyzed by flow cytometry and results are shown in Fig. 2A, indicating that triptolide induced apoptosis on NCI-H295 cells in a dose-dependent manner. NCI-H295 cells were pretreated with pan-caspase inhibitors then with $125 \mu \mathrm{M}$ of triptolide and analyzed for the percentage of viable cells. The results 
A

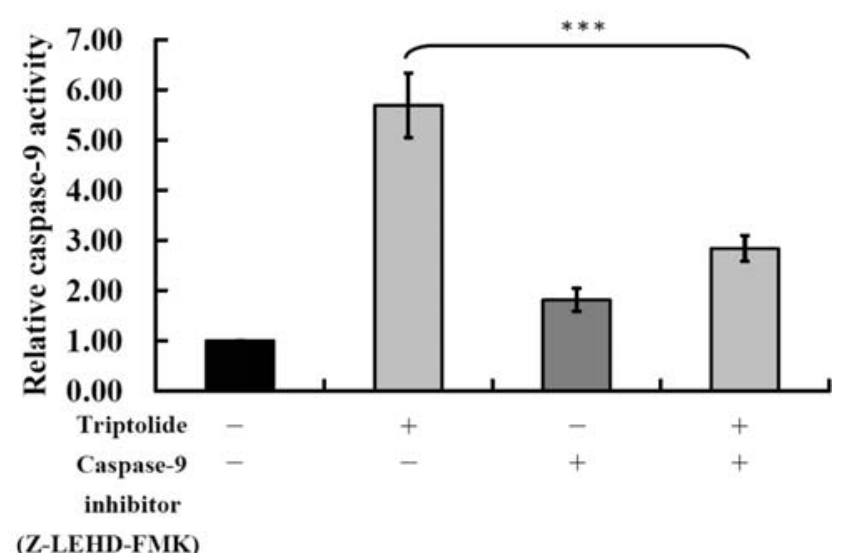

B

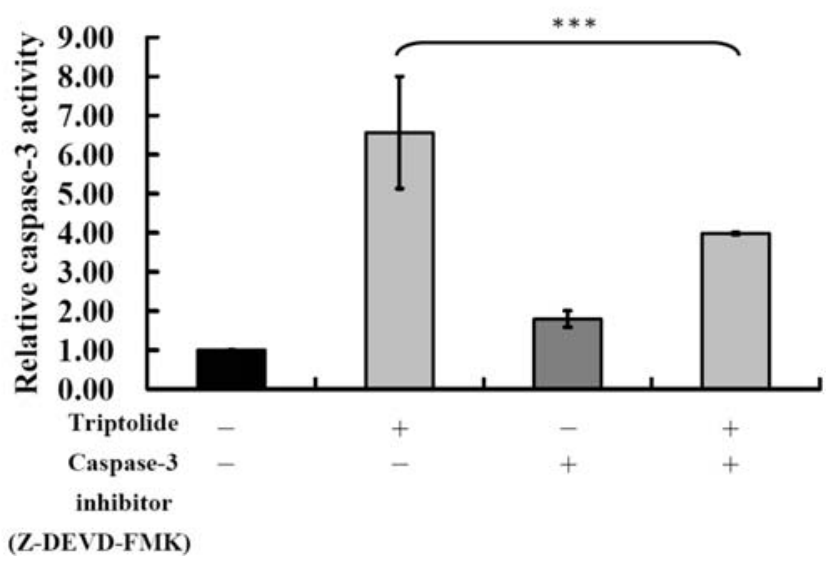

Figure 3. Caspase- 9 and -3 inhibitors inhibited triptolide-induced caspase- 9 and -3 activities in NCI-H295 cells. NCI-H295 cells $\left(5 \times 10^{5}\right.$ cells/well) were pretreated with caspase-3 inhibitor (Z-DEVD-FMK), caspase-9 inhibitor (Z-LEHD-FMK) and pan-caspase inhibitor (Z-VAD-FMK) before cells were treated with $125 \mu \mathrm{M}$ of triptolide then incubated at $37^{\circ} \mathrm{C}, 5 \% \mathrm{CO}_{2}$ and $95 \%$ air for $48 \mathrm{~h}$. Cells were harvested by centrifugation and the cell pellets were add to $50 \mu 1$ of $10 \mu \mathrm{M}$ caspase- 3 and -9 substrate solution. The samples were incubated at $37^{\circ} \mathrm{C}$ for $60 \mathrm{~min}$ before flow cytometric analysis Caspase-3 and -9 activities were detectable in the FL-1 channel (a BD instrument with emission at $525 \mathrm{~nm}$ ). ${ }^{* * *} \mathrm{P}<0.001$ indicates a significant difference from the control.

are shown in Fig. 2B, indicating that triptolide decreased the viable cells, however, the cells pretreated with pan-caspase inhibitors then exposed to triptolide showed an increase in the percentage of viable cells compared to triptolide treatment only.

Caspase-9 and -3 inhibitors inhibite triptolide-induced caspase-9 and -3 activities in NCI-H295 cells. Caspase-9 and -3 play important roles in agent induced apoptosis through a mitochondrial-dependent pathway, furthermore, caspase- 3 is a key executioner of apoptosis, and is responsible for the proteolytic cleavage of many other key proteins such as PARP-1. NC-H295 cells were treated with $125 \mu \mathrm{M}$ triptolide for $48 \mathrm{~h}$ then analyzed by flow cytometric assay and results are shown in Fig. $3 \mathrm{~A}$ and $\mathrm{B}$ indicating that triptolide
A

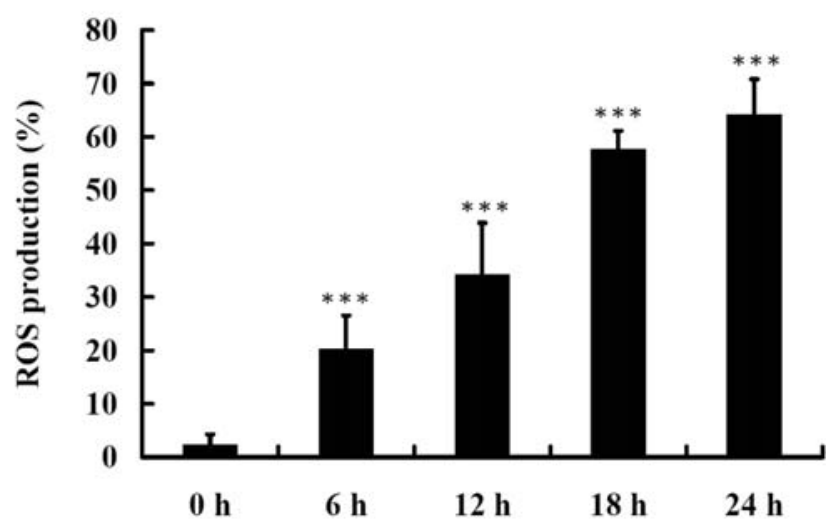

B

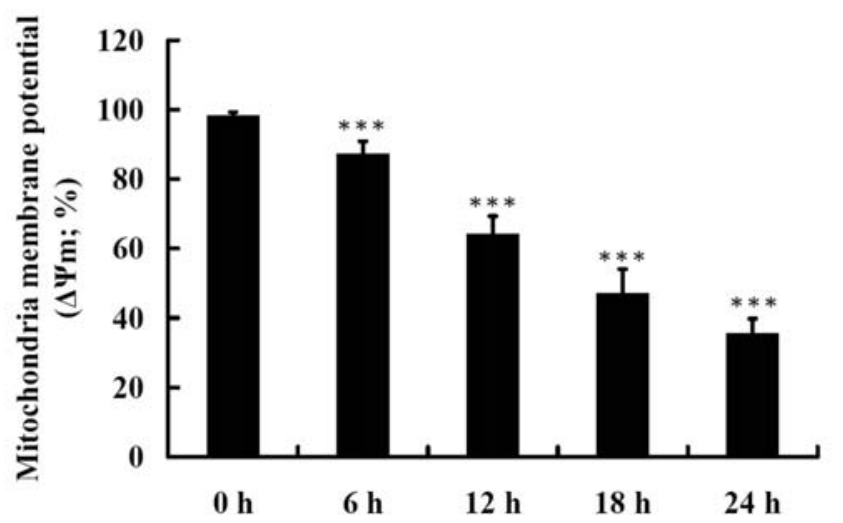

Figure 4. Triptolide affects the production of ROS and the levels of $\Delta \Psi_{m}$ in NCI-H295 cells. NCI-H295 cells $\left(2 \times 10^{5}\right.$ cells $\left./ \mathrm{ml}\right)$ were treated with $125 \mu \mathrm{M}$ of triptolide for $0,6,12,18$ and $24 \mathrm{~h}$. The cells were harvested and resuspended in $500 \mu 1$ of 2,7-Dichlorodihydrofluorescein diacetate (DCFHDA) $(10 \mu \mathrm{M})$ for ROS and in $500 \mu \mathrm{l}$ of DiOC6 $(1 \mu \mathrm{mol} / \mathrm{l})$ for $\Delta \Psi_{m}$. Cells was incubated at $37^{\circ} \mathrm{C}$ for 30 min then were analyzed by flow cytometry. ${ }^{* * *} \mathrm{p}<0.001$ indicates a significant difference from the control.

activated caspase -9 and -3 in a dose-dependent manner. However, the cells pretreated with inhibitors of caspase-9 and -3 and exposed to triptolide showed a decrease in the activation of caspase- 9 and -3 .

Triptolide affects the production of ROS and the levels of $\Delta \Psi_{m}$ in NCI-H295 cells. It is well documented that ROS and mitochondria play an important role in agent-induced apoptosis; therefore, we investigated whether triptolide promoted ROS production and increased the levels of $\Delta \Psi_{m}$ in NCI-H295 cells. NCI-H295 cells were treated with $125 \mu \mathrm{M}$ triptolide for $48 \mathrm{~h}$ then analyzed by flow cytometric assay and the results are shown in Fig. 4A and B. Triptolide activated caspase -9 and -3 in a dose-dependent manner. However, when cells were pretreated with inhibitors of caspase- 9 and -3 and then exposed to triptolide this led to a decrease in the activation of caspase- 9 and -3 .

Triptolide affects the levels of apoptosis-associated proteins in NCI-H295 cells. In order to investigate and confirm the 
A

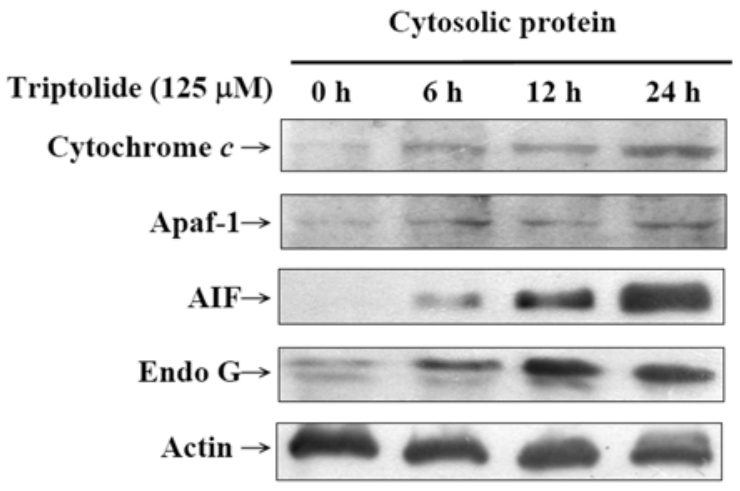

B
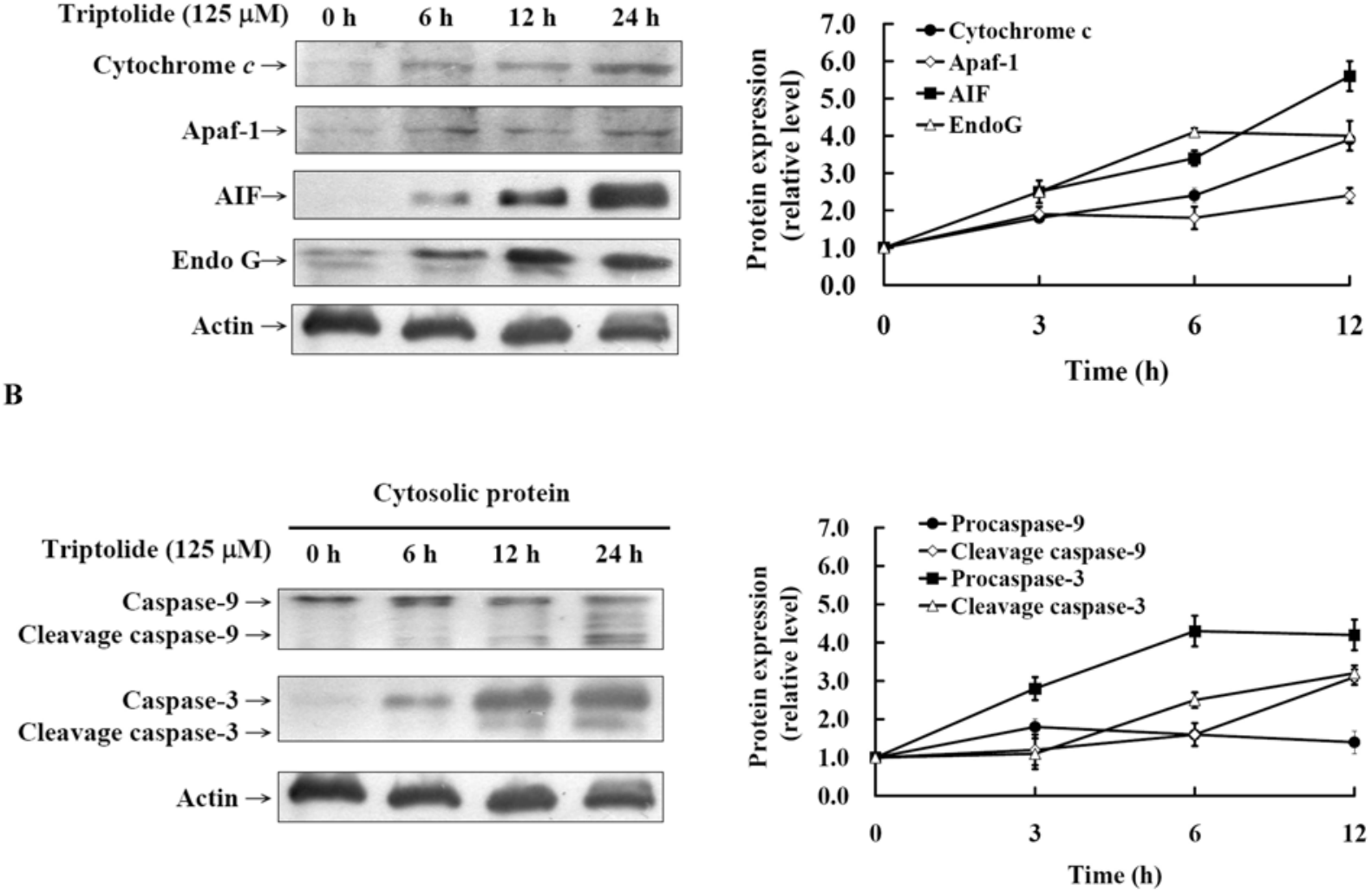

Figure 5. Triptolide affects the protein levels of apoptosis in NCI-H295 cells. The NCI-H295 cells were treated with $125 \mu \mathrm{M}$ triptolide for 0,6 , 12 and $24 \mathrm{~h}$ and the total proteins were prepared, then detected by Western blotting. The primary antibodies for cytochrome c, Apaf-1, AIF and Endo G (A), caspase-9 and caspase-3 were used (B) then each sample was stained by secondary antibody as described in Materials and methods.

\section{$\underline{\text { Triptolide }(125 \mu \mathrm{M})}$}

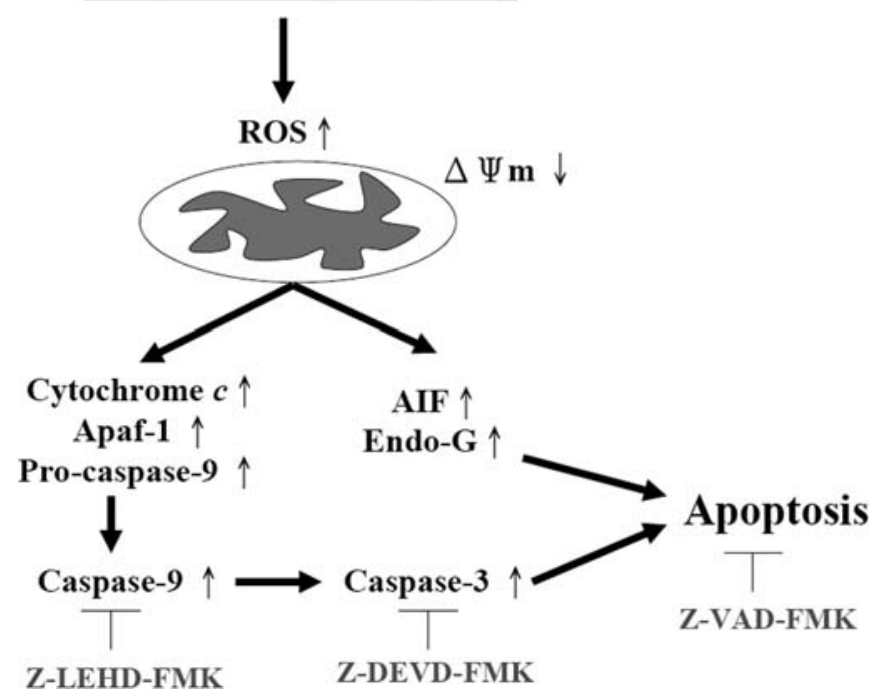

Figure 6. The proposed signaling pathways of triptolide-induced apoptosis in human adrenal cancer NCI-H295 cells are presented.

molecular signaling pathways of triptolide induced apoptosis in NCI-H295 cells, the cells were treated with triptolide and total proteins were collected. Western blotting was used for examining the changes of apoptosis associated proteins and results are shown Fig. $5 \mathrm{~A}$ and $\mathrm{B}$. The results indicated that triptolide promoted the levels of cytochrome c, Apaf-1, AIF and Endo G (Fig. 5A) and activated caspase-9 and -3 (Fig. 5B) which also indicated that triptolide decrease the level of $\Delta \Psi_{m}$ then led to cytochrome c, AIF and Endo G release from mitochondria.

\section{Discussion}

Numerous studies have shown that triptolide has antiinflammatory effects $(22,23)$, contraceptive activity $(24,25)$, and anti-neoplastic abilities $(26,27)$. However, due to it severe toxic effects the clinical use of triptolide is limited. Recently, several investigators demonstrated that triptolide promote apoptosis in a variety of cell types (28-33) including normal human proximal tubular epithelial HK-2 cells in vitro (34). In this study, we report that triptolide induced apoptosis in human adrenal cancer NCI-H295 cells. Triptolide induced significant viability inhibition and morphological changes of cells and induced apoptosis in triptolide-treated NCI-H295 cells. Moreover, triptolide promoted ROS production and dysfunction of mitochondria. Finally, we found triptolide was able to activate caspase- 9 and -3 , thus providing a reasonable explanation for its induction of apoptosis in NCI-H295 cells. These results suggest that triptolide could be usefully investigated as a possible therapeutic agent for adrenal cancer cells. 
Whether the cytotoxicity (decreased the percentage of viable cells) caused by triptolide on NCI-H295 cells is due to apoptosis or necrosis could not be based on the number of viable cells. To clarify this point, we also used Western blotting for examining the changes of apoptotic associated proteins and caspase- 9 and -3 activities in triptolide-treated NCI-H295 cells.

Apoptosis is a tightly regulated autonomously programmed cell death which is involved and utilized extensively during the development and maintenance of tissue and organ homeostasis (35) and elimination of damaged cells. Numerous evidence indicates that many anticancer drugs can cause the death of tumor cells through induction of apoptosis. It is well-known that apoptosis can be divided into two pathways such as the death receptor-mediated extrinsic pathway and the mitochondria-mediated intrinsic pathway $(36,37)$. Our results showed that triptolide induced apoptosis through mitochondria-mediated intrinsic pathway based on several observations such as i) decreased levels of $\Delta \Psi_{m}$; ii) cytochrome c, AIF and Endo G release from mitochondria and iii) activation of caspase- 9 and -3 in examined NCIH295 cells.

It was also reported that mitochondrion plays a critical role in apoptosis induced by some drugs (38). The mitochondrial death pathway is involved in the changes in the permeability of the outer mitochondrial membrane with the collapse of membrane potential $(39,40)$. After the dysfunction of mitochondria cytochrome $\mathrm{c}$ was released and in some signals may also cause AIF and Endo $G$ release from mitochondria. Our results from Western blotting also showed that triptolide increased the release of cytochrome c, AIF and Endo G in NCI-H295 cells. It was reported that the cytosolic cytochrome c from mitochondria binds to Apaf-1, leading to the activation of caspase- 9 , caspase- 3 and poly (ADP-ribose) polymerase $(41,42)$. Caspase- 3 plays an important role in the apoptotic pathways and is expressed in almost all types of cells as inactive pro-enzyme $(43,44)$. Caspase- 3 can be activated by other activated caspases such as caspase- 8 and -9 , and subsequently cleaves some specific substrate, i.e. PARP (45) and the cleavage of DNA repair enzyme PARP resulted in chromosomal DNA break and finally led to apoptosis (46). Our results also clearly showed that triptolide induced similar results. Therefore, we suggest that triptolide induced apoptosis through the mitochondriadependent pathway.

In conclusion, we demonstrated that triptolide significantly induces apoptosis in NCI-H295 cells and the possible signal pathways are shown in Fig. 6. This apoptotic response is associated with the loss of mitochondrial membrane potential, cytochrome c, AIF and Endo G release from mitochondria and activation of caspase- 9 and -3 . Therefore, we believe that triptolide might be a promising molecule in cancer chemoprevention or chemotherapy in adrenal cancer; and further efforts to explore this therapeutic strategy are necessary.

\section{Acknowledgements}

This study was supported by grant CMU96-066 from China Medical University, Taichung, Taiwan.

\section{References}

1. Carter BZ, Mak DH, Schober WD, et al: Triptolide induces caspase-dependent cell death mediated via the mitochondrial pathway in leukemic cells. Blood 108: 630-637, 2006.

2. Jiang X: Clinical observations on the use of the Chinese herb Tripterygium wilfordii Hook for the treatment of nephrotic syndrome. Pediatr Nephrol 8: 343-344, 1994.

3. Tao XL, Sun Y, Dong Y, et al: A prospective, controlled, double-blind, cross-over study of tripterygium wilfodii hook $\mathrm{F}$ in treatment of rheumatoid arthritis. Chin Med J (Engl) 102: 327-332, 1989.

4. Kupchan SM, Court WA, Dailey RG Jr, Gilmore CJ and Bryan RF: Triptolide and tripdiolide, novel antileukemic diterpenoid triepoxides from Tripterygium wilfordii. J Am Chem Soc 94: 7194-7195, 1972.

5. Yang Y, Liu Z, Tolosa E, Yang J and Li L: Triptolide induces apoptotic death of $\mathrm{T}$ lymphocyte. Immunopharmacology 40 : 139-149, 1998.

6. Kiviharju TM, Lecane PS, Sellers RG and Peehl DM: Antiproliferative and proapoptotic activities of triptolide (PG490), a natural product entering clinical trials, on primary cultures of human prostatic epithelial cells. Clin Cancer Res 8: 2666-2674, 2002.

7. Yang S, Chen J, Guo Z, et al: Triptolide inhibits the growth and metastasis of solid tumors. Mol Cancer Ther 2: 65-72, 2003.

8. Westfall SD, Nilsson EE and Skinner MK: Role of triptolide as an adjunct chemotherapy for ovarian cancer. Chemotherapy 54 : 67-76, 2008.

9. Xin MJ, Cui SH, Liu S, et al: Triptolide prolonged allogeneic islet graft survival in chemically induced and spontaneously diabetic mice without impairment of islet function. Hepatobiliary Pancreat Dis Int 9: 312-318, 2010.

10. Lin CC, Yang JS, Chen JT, et al: Berberine induces apoptosis in human HSC-3 oral cancer cells via simultaneous activation of the death receptor-mediated and mitochondrial pathway. Anticancer Res 27: 3371-3378, 2007.

11. Chen YC, Lu PH, Pan SL, et al: Quinolone analogue inhibits tubulin polymerization and induces apoptosis via Cdk1-involved signaling pathways. Biochem Pharmacol 74: 10-19, 2007.

12. Yu FS, Wu CC, Chen CT, et al: Diallyl sulfide inhibits murine WEHI-3 leukemia cells in BALB/c mice in vitro and in vivo. Hum Exp Toxicol 28: 785-790, 2009.

13. Tsou MF, Peng CT, Shih MC, et al: Benzyl isothiocyanate inhibits murine WEHI-3 leukemia cells in vitro and promotes phagocytosis in BALB/c mice in vivo. Leuk Res 33: 1505-1511, 2009.

14. Lu KH, Lue KH, Chou MC and Chung JG: Paclitaxel induces apoptosis via caspase-3 activation in human osteogenic sarcoma cells (U-2 OS). J Orthop Res 23: 988-994, 2005.

15. Yang JS, Chen GW, Hsia TC, et al: Diallyl disulfide induces apoptosis in human colon cancer cell line (COLO 205) through the induction of reactive oxygen species, endoplasmic reticulum stress, caspases casade and mitochondrial-dependent pathways. Food Chem Toxicol 47: 171-179, 2009.

16. Lu CC, Yang JS, Huang AC, et al: Chrysophanol induces necrosis through the production of ROS and alteration of ATP levels in J5 human liver cancer cells. Mol Nutr Food Res 54: 967-976, 2010.

17. Ji BC, Hsu WH, Yang JS, et al: Gallic acid induces apoptosis via caspase- 3 and mitochondrion-dependent pathways in vitro and suppresses lung xenograft tumor growth in vivo. J Agric Food Chem 57: 7596-7604, 2009.

18. Huang YT, Hwang JJ, Lee LT, et al: Inhibitory effects of a luteinizing hormone-releasing hormone agonist on basal and epidermal growth factor-induced cell proliferation and metastasis-associated properties in human epidermoid carcinoma A431 cells. Int J Cancer 99: 505-513, 2002.

19. Chuang JY, Huang YF, Lu HF, et al: Coumarin induces cell cycle arrest and apoptosis in human cervical cancer HeLa cells through a mitochondria- and caspase- 3 dependent mechanism and NF-kappaB down-regulation. In Vivo 21: 1003-1009, 2007.

20. Hsu SC, Kuo CL, Lin JP, et al: Crude extracts of Euchresta formosana radix inhibit invasion and migration of human hepatocellular carcinoma cells. Anticancer Res 27: 2377-2384, 2007.

21. Lu KW, Tsai ML, Chen JC, et al: Gypenosides inhibited invasion and migration of human tongue cancer SCC4 cells through down-regulation of NFkappaB and matrix metalloproteinase-9. Anticancer Res 28: 1093-1099, 2008. 
22. Li FQ, Lu XZ, Liang XB, et al: Triptolide, a Chinese herbal extract, protects dopaminergic neurons from inflammationmediated damage through inhibition of microglial activation. J Neuroimmunol 148: 24-31, 2004.

23. Qiu D and Kao PN: Immunosuppressive and anti-inflammatory mechanisms of triptolide, the principal active diterpenoid from the Chinese medicinal herb Tripterygium wilfordii Hook $\mathrm{f}$. Drugs R D 4: 1-18, 2003

24. Lue Y, Sinha Hikim AP, Wang C, et al: Triptolide: a potential male contraceptive. J Androl 19: 479-486, 1998.

25. Matlin SA, Belenguer A, Stacey VE, et al: Male antifertility compounds from Tripterygium wilfordii Hook f. Contraception 47: 387-400, 1993

26. Shamon LA, Pezzuto JM, Graves JM, et al: Evaluation of the mutagenic, cytotoxic, and antitumor potential of triptolide, a highly oxygenated diterpene isolated from Tripterygium wilfordii. Cancer Lett 112: 113-117, 1997.

27. Wei YS and Adachi I: Inhibitory effect of triptolide on colony formation of breast and stomach cancer cell lines. Zhongguo Yao Li Xue Bao 12: 406-410, 1991.

28. Li W, Liu Y, Li XX, et al: MAPKs are not involved in triptolide-induced cell growth inhibition and apoptosis in prostate cancer cell lines with different p53 status. Planta Med (In press).

29. Borja-Cacho D, Yokoyama Y, Chugh RK, et al: TRAIL and triptolide: an effective combination that induces apoptosis in pancreatic cancer cells. J Gastrointest Surg 14: 252-260, 2010.

30. Lin J, Chen LY, Lin ZX and Zhao ML: The effect of triptolide on apoptosis of glioblastoma multiforme (GBM) cells. J Int Med Res 35: 637-643, 2007.

31. Wan CK, Wang C, Cheung HY, Yang $M$ and Fong WF: Triptolide induces Bcl-2 cleavage and mitochondria dependent apoptosis in p53-deficient HL-60 cells. Cancer Lett 241: 31-41, 2006.

32. Panichakul T, Intachote P, Wongkajorsilp A, Sripa B and Sirisinha S: Triptolide sensitizes resistant cholangiocarcinoma cells to TRAIL-induced apoptosis. Anticancer Res 26: 259-265, 2006 .
33. Yinjun L, Jie $\mathrm{J}$ and Yungui $\mathrm{W}$ : Triptolide inhibits transcription factor NF-kappaB and induces apoptosis of multiple myeloma cells. Leuk Res 29: 99-105, 2005.

34. Shu B, Duan W, Yao J, Huang J, Jiang Z and Zhang L: Caspase 3 is involved in the apoptosis induced by triptolide in $\mathrm{HK}-2$ cells. Toxicol In Vitro 23: 598-602, 2009.

35. Steller H: Mechanisms and genes of cellular suicide. Science 267: 1445-1449, 1995

36. Ashkenazi A and Dixit VM: Death receptors: signaling and modulation. Science 281: 1305-1308, 1998.

37. Green DR and Reed JC: Mitochondria and apoptosis. Science 281: 1309-1312, 1998

38. Liu MJ, Wang Z, Li HX, Wu RC, Liu YZ and Wu QY: Mitochondrial dysfunction as an early event in the process of apoptosis induced by woodfordin I in human leukemia K562 cells. Toxicol Appl Pharmacol 194: 141-155, 2004.

39. Martinou JC and Green DR: Breaking the mitochondrial barrier. Nat Rev Mol Cell Biol 2: 63-67, 2001.

40. Wang X: The expanding role of mitochondria in apoptosis. Genes Dev 15: 2922-2933, 2001.

41. Yang J, Liu X, Bhalla K, et al: Prevention of apoptosis by Bcl-2: release of cytochrome c from mitochondria blocked. Science 275: 1129-1132, 1997.

42. Kluck RM, Bossy-Wetzel E, Green DR and Newmeyer DD: The release of cytochrome $\mathrm{c}$ from mitochondria: a primary site for $\mathrm{Bcl}-2$ regulation of apoptosis. Science 275: 1132-1136, 1997.

43. Enari M, Talanian RV, Wong WW and Nagata S: Sequential activation of ICE-like and CPP32-like proteases during Fasmediated apoptosis. Nature 380: 723-726, 1996.

44. Thornberry NA and Lazebnik Y: Caspases: enemies within. Science 281: 1312-1316, 1998.

45. Wolf BB and Green DR: Suicidal tendencies: apoptotic cell death by caspase family proteinases. J Biol Chem 274: 20049-20052, 1999.

46. Salvesen GS and Dixit VM: Caspase activation: the inducedproximity model. Proc Natl Acad Sci USA 96: 10964-10967, 1999. 